

\title{
O PAPEL DA \\ PSICOLINGUÍSTICA EXPERIMENTAL NO DESENVOLVIMENTO DE MODELOS FORMAL- -COGNITIVOS DE LÍNGUA
}

Eduardo Kenedy Universidade Federal Fluminense

\subsection{CONTEXTO DA DISCUSSÃO}

As contribuições da psicolinguística experimental à linguística teórica já são hoje fartas. Diferentes teorias dentro da linguística reconhecem abertamente a experimentação como um tipo de ciência que pode fazer avançar a discussão sobre 
certos modelos abstratos, já que, com essa abordagem, pode-se tratar os dados disponíveis ao linguista de maneira objetiva, a partir de resultados públicos e mensuráveis que ensejam a replicação e podem ser usados em favor de certas hipóteses cujas previsões são de alguma forma abonadas por experimentos bem elaborados e corretamente conduzidos. Essa opção pela experimentação se vê mesmo fora do campo da linguística gerativa. Vale citar como exemplos Language, usage and cognition (BYBEE, 2010), Constructing a language (TOMASELLO, 2003) e Transitividade traço a traço (ABRAÇADO \& KENEDY, 2013). Na linguística de orientação chomskiana, viu-se recentemente a iniciativa do "Experimental psyscholinguistics: formal approaches" (realizado na Unicamp, em 2010) e o notável número 18 da Revista Virtual de Estudos da Linguagem (ReVEL), de março de 2012, dedicado à sintaxe experimental - sem contar, é claro, o grande número de cursos e livros dedicados ao tema a cada ano ou semestre. A linguística experimental, como se vê, está na ordem do dia.

A aproximação entre a pesquisa experimental sobre a linguagem humana e os modelos abstratos que procuram descrever a competência linguística (no sentido de CHOMSKY, 1965) dos falantes de uma língua natural é por muitos estudiosos considerada natural e esperada - veja-se, por exemplo, Maia (2012), Sprouse e Almeida (2011), Sprouse (2007), Maia e Finger (2005) e Cowart (1997). No entanto, a dialética entre os estudos empíricos a respeito da performance linguística e os modelos abstratos acerca do conhecimento sobre a linguagem tem sido marcada por uma série de desentendimentos e cisões, que em muito prejudicam a desejada articulação entre a psicolinguística e linguística gerativa. O propósito deste artigo é descrever um pouco da história das últimas décadas, com o surgimento e o amadurecimento que se deram, de forma independente, na psicolinguística e na teoria linguística compreendida aqui como gerativismo ou formalismo. Pretende-se descrever e comentar os momentos de aproximação e distanciamento entre as áreas ao longo desses anos, de modo a encaminhar a exposição ao que se sustentará ser o amplo programa de trabalho em conjunto que emergiu mais recentemente com as propostas minimalistas (cf. CHOMSKY, 1995, 2001, 2002, 2007, 2011). Trata-se, na verdade, de uma história bem conhecida dos psicolinguistas, a qual se relata aqui pela necessidade de explicitá-la aos próprios gerativistas e a um público de linguistas mais amplo.

$\mathrm{O}$ artigo está organizado nas sete seções. Na segunda delas, faz-se uma descrição dos propósitos científicos da psicolinguística, bem como uma caracterização de sua verve metodológica. Na seção imediatamente seguinte, considera-se a linguística gerativa em seus aspectos teóricos e metodológicos que se mantém ativos e importantes até o presente. $\mathrm{Na}$ quarta seção, apresenta-se uma reflexão de cunho histórico acerca dos pontos de aproximação e de separação entre psicolinguística experimental e gerativismo. Tal reflexão encaminha o artigo para 
sua próxima seção (numerada como 8.5), na qual se explicita de que maneira o Programa Minimalista chomskiano oferece uma oportunidade de ressignificação para a dicotomia competência vs. desempenho, ensejando o trabalho integrado entre a pesquisa empírica da psicolinguística e a formulação de modelos abstratos na teoria linguística. $\mathrm{O}$ sexto item apresenta dois dos principais equívocos que precisam ser evitados na busca da correta articulação entre psicolinguística e gerativismo, bem como descreve dois tipos de pesquisa experimental que procuram articular-se a modelos formais de gramática: o MINC (CORRÊA \& AUGUSTO, 2007) e a pesquisa sobre encaixamento recursivo central de orações relativas (KENEDY, a sair). No item 8.7, são apresentadas considerações gerais, de caráter conclusivo, que encerram o artigo.

\subsection{PSICOLINGUÍSTICA}

O desenvolvimento da psicolinguística, no seio da psicologia cognitiva, deu-se de maneira distante e independente da teoria linguística. Com efeito, pode-se dizer que a criação objetiva da área aconteceu na virada do século XIX para o século XX, quando Wundt, ao criar o que seria o primeiro laboratório de psicologia experimental da História, em 1879, reconheceu a existências da subdisciplina Sprachpsychologie, que deveria estudar como a mente humana faz emergir a linguagem para a produção e a compreensão linguística. $\mathrm{O}$ projeto original de Wundt só seria retomado, de fato, nos anos 1950/1960, do século XX, após as décadas do hiato behaviorista, sua derrocada e a ascensão das ciências cognitivas, notadamente com o trabalho de Miller e colegas (1962, 1963). Mas o fato é que a concepção de Wundt, adaptada nos anos 60 pelos psicólogos cognitivos, é ainda correta para a compreensão do lugar da psicolinguística no empreendimento das ciências em geral. De acordo com tal concepção, a psicolinguística deve investigar como o fenômeno da linguagem emerge na mente humana, a partir do funcionamento, em tempo real, de diversos recursos cognitivos (dentro os quais, o "módulo" ou “órgão" especificamente linguístico, se existir), recursos esses que interagem para dar à luz nossa capacidade de produzir e compreender a fala (e eventualmente a escrita). Esse "emergir" da linguagem na mente é de tal maneira amplo que, estrategicamente, a psicolinguística se divide em pelo menos duas subdisciplinas ou subáreas, uma dedicada à origem da capacidade linguística no indivíduo (a aquisição da linguagem, no sentido de aquisição da língua do ambiente pelo bebê e pela criança) e outra dedicada ao uso da linguagem por adultos, em que o termo "uso" por conveniência é denominado "processamento linguístico". Além disso, evidentemente, existe na psicolinguística amplo espaço para a pesquisa sobre a aquisição anormal da linguagem e sobre o processamento linguístico em indivíduos com 
alguma patologia neuropsicológica, bem como sobre a eventual perda da capacidade linguística em decorrência de problemas neurológicos.

De maneira bem resumida (porém correta), é possível dizer que a premissa fundamental da psicolinguística é observar o desempenho humano em ambiente controlado (laboratório) para dele aferir certas medidas comportamentais (como, dentre outras, o tempo de reação, movimentos oculares, respostas elicitadas, apontamento de figuras, julgamento de aceitabilidade), medidas essas que serão usadas como evidências em favor de certas previsões de um dado modelo de funcionamento da linguagem na mente. Metodologicamente, pode-se caracterizar a psicolinguística como uma ciência que assume o método hipotético-dedutivo proposto por Popper (1959), no sentido de que seus objetos são proposições que podem ser falseadas de acordo com modelo de testagem de previsões. Essencialmente, os dados que alimentam as pesquisas psicolinguísticas são de natureza experimental, o que significa que se trata de dados públicos e manipulados. Tais dados são obtidos por meio de diversas técnicas de pesquisa, como, por exemplo, leitura e audição segmentadas, rastreamento ocular, decisão lexical, priming, julgamento imediato de aceitabilidade, monitoramento de fonemas, locação de cliques, identificação cromática, dentre outras. Essas técnicas podem aferir dados durante o processamento da informação linguística (on-line) ou após a conclusão do processamento linguístico (off-line). Os dados obtidos por meios desses paradigmas são submetidos às análises estatísticas adequadas, com os testes de normalidade, testagem de hipótese etc. e, com base nos seus respectivos resultados, são feitas generalizações a respeito do comportamento linguístico relevante em condições de compreensão ou de produção específicas.

De fato, pode-se afirmar com segurança que o modo de ser e o modo de fazer da psicolinguística contemporânea não se distinguem do modo de fazer e do modo de ser do restante das ciências da cognição.

\subsection{GERATIVISMO}

A fundação da linguística gerativa, como uma entre as novas ciências da mente, se dá, como se sabe, com o trabalho individual de Chomsky, nas décadas de 1950 e 1960. As ideias de Chomsky foram muito bem recebidas no então emergente conjunto das ciências cognitivas e, de certa forma, têm o crédito de abreviar os últimos momentos do behaviorismo como paradigma dominante na psicologia. Para compreendermos corretamente a história (e o fenômeno) da linguística gerativa, propõe-se aqui a seguinte divisão em dois eixos. O primeiro deles é justamente o que estabelece, com clareza, a linguística gerativa como uma das ciências cognitivas. Chame-se esse eixo de gerativismo epistemológico. É nesse eixo que o discurso chomskiano faz a correta identificação da linguagem como fenômeno cognitivo, retomando explicitamente a tradição de Port-Royal, 
de Descartes e outros racionalistas. É nele que são formulados o problema de Platão, o problema lógico da aquisição da linguagem, o argumento da pobreza de estímulo, a hipótese inatista, a teoria de princípios e parâmetros e o próprio programa minimalista. O outro eixo é relativamente independente do primeiro. Pode-se denominá-lo gerativismo metodológico. Ele diz respeito ao trabalho teórico do linguista em seu empreendimento de descrever os detalhes do conhecimento linguístico humano, nos níveis fonológico, morfológico, sintático etc. Um outro nome para o gerativismo metodológico é formalismo.

Em termos bem gerais, pode-se afirmar que o gerativismo metodológico se caracteriza pela adoção do método dedutivo. Isso quer dizer que um gerativista assume certos axiomas sobre a linguagem na mente, ou sobre certos fenômenos em particular. Tais axiomas são motivados por observações particulares de usos da linguagem, pela intuição ou imaginação do próprio linguista e são conduzidos por meio de argumentações conceituais. É a partir desses axiomas que o gerativista poderá derivar dedutivamente suas análises linguísticas. Essas análises são quase exclusivamente conduzidas com base em dados retirados da intuição linguística do próprio teórico, na forma dos conhecidos julgamentos de aceitabilidade informais gerativistas. Isso significa que os dados de um trabalho gerativista típico são privados e manipulados.

É correto dizer que o modo de ser e o modo de fazer do gerativismo metodológico são singulares quando comparados às demais ciências da cognição.

\subsection{IDENTIDADES E CISÃO}

As relações entre psicolinguística e gerativismo (pelo menos no eixo epistemológico) parecem óbvias e imediatas, tanto que as disciplinas cresceram como irmãs nos anos 1950 e 1960. Muitos psicolinguistas acreditavam que as transformações postuladas pelos sintaticistas de orientação chomskiana não eram apenas uma ferramenta descritiva útil, uma maneira puramente formal e abstrata de descrever um fenômeno linguístico. Pelo contrário, todos pareciam acreditar que as transformações eram genuínas computações mentais que, como quaisquer outras, poderiam ser capturadas pelos paradigmas metodológicos da psicologia cognitiva.

De fato, certos trabalhos publicados nos anos 1960 pareciam encontrar evidências em favor das previsões que podiam ser formuladas com base em certas hipóteses ou modelos transformacionais (cf. MILLER (1962), MILLER \& CHOMSKY (1963) e MCMAHON (1963)). No entanto, a maior parte desse trabalho foi um fracasso, o que precipitou um crescente afastamento entre as duas áreas (cf. BEVER, FODOR, GARRET \& MEHLER (1966), FODOR, BEVER \& GARRET (1974)). Para entender esse “fracasso", pense-se num exemplo grosseiro: se um gerativista postulasse que a derivação de uma frase negativa ocorria a 
partir de uma computação por sobre uma frase afirmativa, então a derivação de uma estrutura negativa deveria ser considerada computacionalmente mais complexa do que a de uma afirmativa, o que permitiria certa previsão num teste experimental (por exemplo, uma negativa demandará mais tempo de reação num teste de leitura). No caso, previsões como essas muitas vezes não se confirmavam.

Analisando esse "fracasso" em retrospectiva, uma decisão racional que poderia ser tomada naquele momento da história seria reformular a natureza dos modelos formais de então, que pareciam não espelhar algo que fosse detectável como psicologicamente real. Essa talvez fosse uma solução sensata se, de fato, se objetivasse a formulação de modelos formais que conseguissem espelhar, ainda que de forma aproximada e imperfeita, a cognição linguística real - usando, para tanto, dados de diferentes fontes (e não apenas essencialmente os dados intuitivos) de modo a buscar uma identidade entre as computações virtuais postuladas pelos formalistas e as computações reais que psicolinguistas e neurocientistas tentam observar. Infelizmente, a história registrou um movimento separatista que rumou em direção oposta. Com a formulação da dicotomia competência x desempenho, o objeto da linguística gerativa passava a ser a linguagem tomada de uma maneira ultra abstrata - a competência linguística de um falante-ouvinte ideal, que conhece sua língua perfeitamente, cresceu e habita numa comunidade linguística perfeitamente homogênea e não é afetado por questões de memória ou concentração em seu saber sobre a linguagem (CHOMSKY, 1965, p. 84). De certa forma, a dicotomia fazia crer que testes psicolinguísticos não poderiam capturar a realidade psicológica das transformações porque essas são de tal maneira abstratas que não se deixariam mensurar a partir do desempenho concreto e observável.

A dicotomia cindia, de um lado, o gerativismo epistemológico, que manteve e mantém até o presente o discurso sobre a linguagem como um órgão da mente, reafirmando a linguística gerativa como uma das ciências cognitivas, deixando, de outro lado, o gerativismo metodológico, que se aprofundava em modelos formais cada vez mais afastados do uso cognitivo da linguagem em tempo real. A independência entre competência e desempenho ou, noutras palavras, entre computações virtuais (formais) e computações reais, foi tomada, ao longo de décadas, muitas vezes de maneira um tanto radical. Para um observador externo, muito do fazer formalista do gerativismo metodológico ou não se relaciona ou se relaciona apenas de maneira muito remota ao discurso do gerativismo epistemológico.

\subsection{DIÁLOGOS REABERTOS COM O PROGRAMA MINIMALISTA}

É possível dizer que a cisão entre as duas áreas vigorou por longos anos, e foi somente com o advento do programa minimalista, mais decisivamente na segunda 
metade dos anos 1990, que os diálogos foram reabertos. O programa minimalista (CHOMSKY, desde 1995 e até o presente) assume que a faculdade da linguagem é de fato um subsistema cognitivo, acoplado nos sistemas de desempenho, que Chomsky nomeia de sistemas superiores. Esses sistemas são muito complexos e diversos, mas é possível compreendê-los esquematicamente como dois grandes sistemas: o sistema articulatório-perceptual (ou sensório-motor), responsável para exteriorização e internalização do sinal físico que veicula representações linguísticas, e o sistema conceitual-intencional (ou sistemas de pensamento), que alimenta ou retira da linguagem informações de natureza comunicativa, conceitual, referencial etc., e que também acessa e mantém ativas na memória de trabalho certas informações cognitivas necessárias para a derivação de estruturas sintáticas. Muitas vezes, faz-se referência a esses dois grandes sistemas como sistemas de interface.

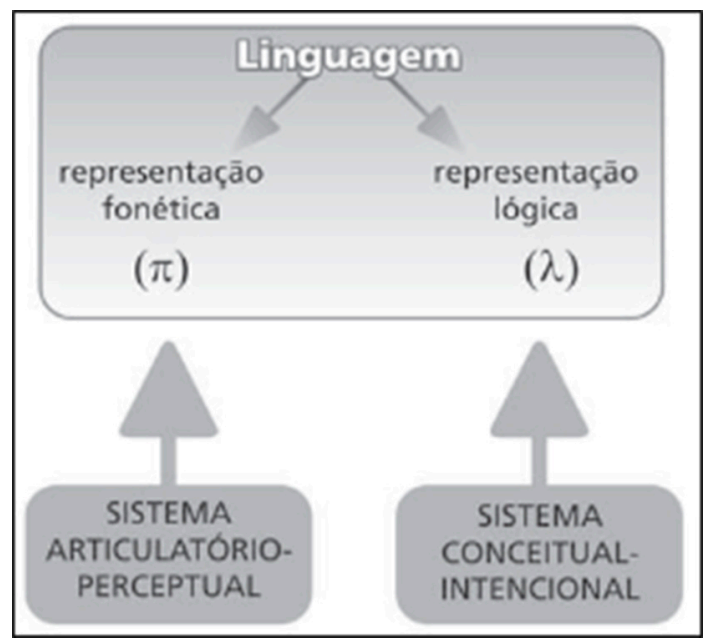

Figura 8.1 A arquitetura minimalista da Faculdade da Linguagem.

Em diversos momentos de sua obra ao longo desses 20 anos de minimalismo, Chomsky tem deixado claro que a faculdade da linguagem se subordina às suas interfaces tanto em termos funcionais, no tempo real da mente de qualquer indivíduo, quanto no que diz respeito à sua origem, na evolução humana. Sua fábula evolucionária deixa isso muito claro, como se vê a seguir em tradução livre.

Imagine um primata com a arquitetura mental humana e com o aparato sensório-motor adequado, mas sem um órgão da linguagem. Esse primata teria nossos modos de organização perceptual, nossas atitudes proposicionais (crenças, desejos, esperanças, medos...) na medida em que essas não são mediadas pela linguagem, talvez uma "linguagem do pensamento", no sentido de Jerry Fodor, mas nenhuma maneira de expressar os seus pensamentos por meio de expressões linguísticas, de tal forma que esses permaneceriam quase completamente inacessíveis para si próprio e para 
os outros. Suponha que algum acontecimento reorganize o cérebro desse primata de modo que a Faculdade da Linguagem possa emergir. Para poder ser usado, esse novo órgão deve obedecer a certas 'condições de legibilidade' impostas pelas interfaces. (CHOMSKY, 2001, p. 6-7)

A arquitetura cognitiva minimalista e o respectivo nicho da linguagem nela assumido é muito bem conhecida dos atentos à literatura chomskiana. O que não é tão notória é a reanálise das noções de competência e desempenho - e, consequentemente, a reanálise da separação entre teoria linguística e psicolinguística - que tal arquitetura evoca. Por exemplo, ao justificar a convergência de uma derivação tendo em vista o princípio da interpretação plena, um gerativista está assumindo que, por alguma razão, são as interfaces da linguagem que licenciam uma representação do par \{som e significado\}. Ora, ao fazer isso, esse teórico deverá assumir, ainda que tacitamente, que questões relacionadas ao uso da linguagem (tais como memória, atenção, concentração, integração de informação etc.) são as que, de fato e em última instância, explicam a razão pela qual uma derivação é convergente (ou não). O que aqui se deve explicitar e enfatizar é que a arquitetura cognitiva proposta pelo programa minimalista, quando tomada seriamente, não apenas permite, mas de fato induz os linguistas a conduzir os estudos sobre a competência linguística humana a partir das descobertas sobre o desempenho - no conjunto das pressões cognitivas que fazem a linguagem ser como é e proceder derivações tal como procede.

\subsection{CAMINHOS PARA UMA MAIOR E MELHOR ARTICULAC̣ÃO}

Naturalmente, integrar psicolinguística e linguística formal não é fácil, nem simples. Com efeito, há muitas maneiras equivocadas de entender as relações entre psicolinguística e teoria da gramática. Vejam-se duas delas. O primeiro equívoco na busca de articulação entre as duas áreas é não reconhecer a distância que separa, de um lado, muitos modelos concebidos via gerativismo metodológico e, de outro lado, o discurso cognitivista do gerativismo epistemológico. Reconhecer a diferença entre modelos formais e modelos cognitivos em linguagem é o primeiro passo para a possível aproximação entre formalismo e psicolinguística. Tal reconhecimento está longe de ser prática comum entre gerativistas, tanto que é frequente que, entre eles, modelos cognitivos e modelos formais sejam tomados como termos sinônimos, num claro caso de non sequitur. Tomar o formal como necessariamente cognitivo é um erro gerativista naturalizado, justamente porque se repete ao longo do tempo e há muito tempo. Apenas a título de ilustração: houve na Abralin 2011, em Curitiba, uma mesa de debates que se intitulava "Repesando as fronteiras entre teoria gramatical, psicolinguística e aquisição da 
linguagem" e nela, alguns pesquisadores afirmaram que as fronteiras entre essas três áreas do conhecimento são artificiais. Um deles chegou a infelizmente dizer que "tudo é psicolinguística", desde a formulação teórica de uma árvore sintática abstrata, até o trabalho laboratorial de um neurocientista da linguagem. Pelo que já até já se expôs, é fácil entender por que as afirmações dos colegas dessa mesa não estão corretas. Dizer que "tudo é psicolinguística" só faz sentido se pensamos no gerativismo epistemológico, mas o salto entre esse eixo e o eixo metodológico não é automático, ao contrário do que aquela fala infeliz quis fazer crer.

O segundo equívoco é decorrente do primeiro. Ele acontece quando se interpreta que a psicolinguística seja uma espécie de apêndice da teoria gerativa. Algo como uma "zona de testagem", cuja utilidade é buscar comprovação laboratorial, em termos de realidade psicológica, dos construtos concebidos pelo teórico com base em suas intuições. Para ilustrar esse erro, pense-se numa importante formalista brasileira, que disse honestamente num evento em 2012: "A relação com a psicolinguística é importante porque nós temos a teoria e eles têm a prática”. Naturalmente, isso também não está correto. $\mathrm{Na}$ verdade, a construção do conhecimento depende visceralmente do tipo de dado de que o pesquisador dispõe, é por isso que a convergência de dados coletados a partir de diferentes abordagens que trabalhem em conjunto e de maneira integrada (dados como os da introspecção, os da experimentação psicolinguística e os obtidos por metodologias da neurociência da linguagem) é um movimento crucial para fazer avançar o conhecimento cientifico sobre a linguagem. Isso não tem quase nada a ver com a proposta de usar a metodologia experimental como instrumento na busca de evidência empírica em favor modelos ou hipóteses concebidos a partir de uma metodologia tão diversa e independente, como a intuição e o dedutivismo, típicos na teoria da gramática.

Deixando de lado esses dois grandes erros, é importante citar neste artigo um trabalho que positivamente vem unindo metodologia experimental e formalismo de uma maneira muito interessante. Trata-se do MINC, Modelo Integrado de Computação On-line (CORRÊA \& AGUSTO, 2007). O modelo assume a arquitetura minimalista chomskiana (CHOMSKY, 1995, 2007) e sustenta que, na produção linguística, a composição da Numeração e seus subarranjos é disparada pelo "planejamento de fala", instância cognitiva de interface, enquanto, na compreensão linguística, o acesso lexical é o elemento disparador das computações sintáticas. Além disso, o modelo adota uma direcionalidade mista para as derivações sintáticas, no sentido de que elementos funcionais disparam computações top-down acessadas pelos sistemas intencionais, enquanto itens lexicais disparam computações bottom-up a partir de seus predicadores e são acessados pelos sistemas conceituais. O modelo prevê também dois tipos de operação Move (regra de Movimento), um disparado pela mera questão de linearização parametrizada na ordem canônica adquirida na infância (a qual não demanda custo computacional) 
e outro disparado por demandas discursivas específicas (que possuem custo de computação). Esse modelo é capaz de descrever de maneira formalmente elegante e psicologicamente motivada diversos tipos de derivação sintática.

Além do MINC, trabalhos recentemente desenvolvidos pelo Laboratório de Psicolinguística da Universidade Federal Fluminense (Gepex-UFF) vêm buscando a integração entre pesquisa experimental e modelos formais de língua. Particularmente, os trabalhos do Gepex estão investigando o papel da articulação entre informações sintáticas e informações discursivas ativas na memória de trabalho, no curso da representação mental de frases durante a compreensão, como fator crucial para o cálculo da complexidade sintática de representações linguísticas. Experimentos de julgamento de aceitabilidade, aplicados com estudantes universitários, e experimentos off-line de compreensão e paráfrase de frases, aplicados com crianças no quinto ano de escolarização, vêm indicando que o tipo de referente discursivo que é preciso manter ativo na memória durante a computação de orações relativas de encaixe central é uma variável fundamental para que esse tipo de estrutura seja mentalmente computada pelas pessoas. Tais pesquisas perseguem o ideário minimalista de incorporar as interfaces ao estudo da linguagem, de modo a compreender como o sistema linguístico consegue satisfazer a demanda dos sistemas de desempenho, com destaque para a memória de trabalho.

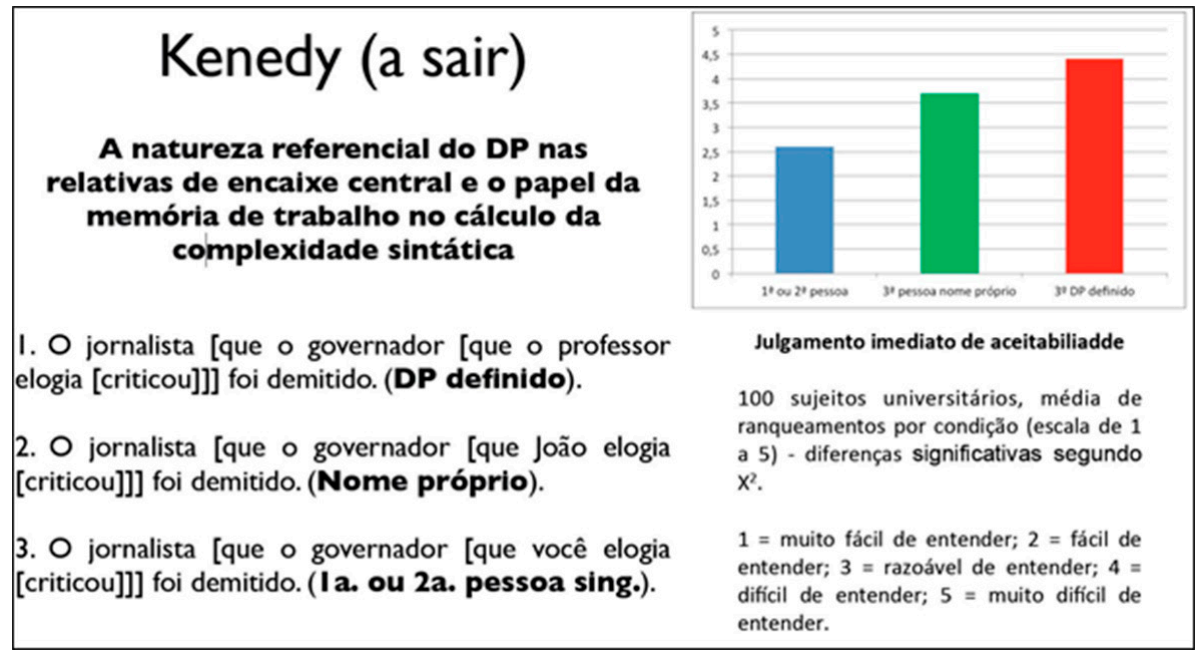

Figura 8.2 Resultados do experimento de Julgamento imediato de aceitabilidade.

Os resultados do experimento de Julgamento imediato de aceitabilidade indicam que as estruturas com orações relativas de encaixamento central recursivo, como os exemplos 1, 2 e 3 da Figura 8.2, tornam-se mais fáceis de processar cognitivamente quando a entidade discursiva presente no segundo encaixamento 
sintático é um pronome da primeira ou da segunda pessoa do discurso, itens que são considerados de baixa ou nula carga informacional em termos de permanência na memória de trabalho (cf. GIBSON, 2000). Os 100 sujeitos universitários participantes do experimento julgaram estruturas desse tipo com 2,5 pontos médios, numa escala de 0 a 5 pontos de complexidade, em que 5 indicava a complexidade máxima (para a compreensão do enunciado) e 0 indicava a complexidade mínima. A aceitabilidade das relativas de encaixe central decrescia quando um nome próprio era introduzido como uma nova entidade discursiva no segundo encaixe da relativa complexa. Nesse caso, a estrutura recebia o escore 3,6 pontos, significativamente superior ao escore do encaixamento com pronomes de primeira e segunda pessoas. A complexidade máxima, com a mais alta dificuldade para o processamento cognitivo, era atingida quando o segundo encaixamento da relativa introduzia uma expressão referencial definida $(\mathrm{O}$ sintagma determinante pleno - DP, na sigla em inglês). Nesse caso, os escores de dificuldade associados ao encaixamento da relativa chegavam à beira dos 4,5 pontos.

O comportamento identificado entre adultos no experimento de aceitabilidade encontrou um correlato quase perfeito no experimento de compreensão e paráfrase aplicado com 40 crianças, estudantes do $5^{\circ}$ ano de escolarização de uma escola pública de Niterói/RJ, com idade média de 11 anos. Nesse experimento, as crianças eram instadas a escolher, entre duas opções destacadas num formulário impresso, a frase que melhor parafraseava um enunciado apresentado por escrito, conforme se ilustra na Figura 8.3.



Figura 8.3 Resultados do experimento de Leitura e paráfrase.

No caso, as crianças identificaram corretamente a paráfrase das relações semânticas do enunciado-estímulo, que continha uma oração relativa de encaixe 
central (somente um encaixe), quando o sujeito da relativa apresentava um pronome de primeira ou segunda pessoa do discurso. Nessa condição, ilustrada em 1, na sequência 1, 2 e 3 da Figura 8.3, as crianças alcançavam um pouco mais de $80 \%$ na indicação de paráfrases corretas. Já quando o sujeito da relativa era uma entidade discursiva cognitivamente mais custosa, como um nome próprio, os acertos na paráfrase caíam para $60 \%$. A escolha aleatória da paráfrase ocorria sempre que o sujeito da relativa encaixada ao centro apresentava um DP pleno.

Essa rápida demonstração informal dos resultados de dois experimentos aplicados recentemente se presta a indicar que muitas questões sintáticas que estão no coração das hipóteses gerativistas - e as relativas de encaixamento recursivo central são sem dúvida uma delas - podem apresentar sua percepção alterada, nos "julgamentos de gramaticalidade" característicos do trabalho de linguistas de orientação chomskiana, em razão de variáveis não estritamente sintáticas que escapam ao modelo formal clássico. No caso, a pesquisa do Gepex explorou questões da memória de trabalho, como o tipo de entidade discursiva a ser mantida em buffer durante a computação sintática, que talvez sejam essenciais para caracterizar nossa capacidade linguística na compreensão de frases com esse tipo de estrutura. De fato, tal pesquisa fundamentalmente propõe o olhar para as interfaces na busca de compreensão sobre como a linguagem obedece suas imposições, conforme o minimalismo chomskiano propõe. Incorporar os estudos das interfaces aos estudos sobre a competência linguística, e fazê-lo de maneira de fato integrada ao espírito da pesquisa experimental, pode ser um bom caminho para que as contribuições que a psicolinguística possa oferecer à teoria da gramática ganhem realidade prática e façam avançar as ciências da linguagem.

\subsection{PARA CONCLUIR}

A articulação entre psicolinguística e gerativismo provavelmente provocará em breve uma reanálise ou, pelo menos, uma ampla discussão a respeito da oposição competência vs. desempenho. Com efeito, as distinções entre saber e fazer, representação e acesso, teoria e processamento parecem indicar diferentes grandezas ontológicas, das quais herdaríamos inapelavelmente a realidade teórica (da linguística formal) e a realidade psicológica (da psicolinguística). Muitos linguistas e diversos filósofos da ciência são contundentes ao afirmar que, para o bem do progresso científico, tais realidades devem ser coerentemente articuladas na dialética entre teoria e experimentação, mas elas jamais poderão ser de fato integradas - tal como a física teórica não se reduz à física experimental. Quando perguntado recentemente sobre a validade contemporânea de sua clássica dicotomia, Chomsky reafirmou-a como uma necessidade conceitual. Para ele, as pessoas sabem coisas e as pessoas fazem coisas, sendo a oposição entre saber e fazer uma 
imposição do mundo natural. Nesse cenário, tal como sugere a agenda do programa minimalista, a dicotomia mantém-se, mas a realidade da competência linguística não deverá ser construída ex nibilo, como foi e perigosamente pode ainda continuar a ser a tradição formalista chomskiana. Se a interpretação do programa minimalista que aqui se defende for levada a sério, então se deve entender que as descobertas dos estudos sobre o desempenho são a principal fonte de informação para a formulação de uma teoria empiricamente adequada acerca da competência linguística humana.

\section{REFERÊNCIAS}

ABRAÇADO, J.; KENEDY, E. Transitividade traço a traço. EDUFF: Niterói, 2013. BEVER, T. et al. Transformational operations and stimulus complexity. Unpublished paper, MIT, 1966.

BYBEE, J. Language, usage and cognition. Cambridge: Cambridge University Press, 2010. CHOMSKY, N. Language and other cognitive systems: what is special about language? In: Language Learning and Development. London: Psychology Press, 2011.

. Of minds and language. Biolinguistics, v. 1, n. 1, 2007.

. Beyond explanatory adequacy. In: BELLETTI, A. (Ed.). Structures and Beyond: The Cartography of Syntactic Structures. Oxford: Oxford University Press, 2002. v. 3.

. Derivation by phase. MIT Occasional Papers in Linguistics, v. 18. [Versão revisada publicada em Chomsky, 2001], 1999.

. The Minimalist Program. Cambridge: MIT Press, 1995.

. Aspects of the Theory of Syntax. Cambridge: MIT Press, 1965.

CORRÊA, L. M. S.; AUGUSTO, M. R. A. Computação linguística no processamento online: soluções formais para a incorporação de uma derivação minimalista em modelos de processamento. Cadernos de estudos linguísticos, Campinas, v. 49, p. 167-183, 2007. COWART, W. Experimental syntax: applying objective methods to sentence judgments. London: Sage Publications, 1997.

FODOR, J.; BEVER, T.; GARRET, M. The psychology of language: an Introduction to Psycholinguistics and Generative Grammar. New York: McGraw-Hill, 1974.

GIBSON, E. The dependency locality theory: a distance-based theory of linguistic complexity. In: MIYASHITA, Y., MARANTZ, A.; O'NEIL, W. (Ed.). Image, language, brain. Cambridge: MIT Press 2000. p. 95-126.

KENEDY, E. Referentes discursivos e memória de trabalho no cálculo da complexidade sintática: um estudo experimental com orações relativas de encaixe recursivo central. (No prelo).

MAIA, M. Sintaxe experimental: uma entrevista com Marcus Maia. ReVEL, v. 10, n. 18, 2012.

MAIA, M.; FINGER, I. Processamento da linguagem. Educat: Pelotas, 2005. 
MacMAHON, L. Grammatical analysis as part of understanding a sentence.

Cambridge: 1963.

MILLER, G. Some psychological studies of grammar. American psychologist, v. 17, p. 748-762, 1962.

MILLER, G.; CHOMSKY, N. Introduction to the formal analysis of natural languages. In: LUCE, D. L; BUSH, R. R.; GALANTER, E. (Ed.). Handbook of mathematical psychology. New York: Wiley, 1963. p. 269-321. v. 3

POPPER, K. The logic of scientific discovery. New York, 1959.

SPROUSE, J. A program for experimental syntax: finding the relationship between acceptability and grammatical knowledge. University of Maryland, 2007.

SPROUSE, J.; ALMEIDA, D. The 469 data points that form the empirical foundation of generative syntactic theory are at least $98 \%$ replicable using formal experiments. (No prelo). TOMASELLO, M. Constructing a language: a usage-based theory of language acquisition. Cambridge: Harvard University Press, 2003. 